\title{
Affibody Molecules for Epidermal Growth Factor Receptor Targeting In Vivo: Aspects of Dimerization and Labeling Chemistry
}

Vladimir Tolmachev ${ }^{1-3}$, Mikaela Friedman ${ }^{4}$, Mattias Sandström ${ }^{5}$, Tove L.J. Eriksson², Daniel Rosik ${ }^{2}$, Monika Hodik ${ }^{1}$, Stefan Ståhl ${ }^{4}$, Fredrik Y. Frejd ${ }^{1,2}$, and Anna Orlova ${ }^{1,2}$

${ }^{1}$ Unit of Biomedical Radiation Sciences, Rudbeck Laboratory, Uppsala University, Uppsala, Sweden; ${ }^{2}$ Affibody AB, Bromma, Sweden; ${ }^{3}$ Department of Medical Sciences, Nuclear Medicine, Uppsala University, Uppsala, Sweden; ${ }^{4}$ Division of Molecular Biotechnology, School of Biotechnology, Royal Institute of Technology, Stockholm, Sweden; and ${ }^{5}$ Section of Hospital Physics, Department of Oncology, Uppsala University Hospital, Uppsala, Sweden

Noninvasive detection of epidermal growth factor receptor (EGFR) expression in malignant tumors by radionuclide molecular imaging may provide diagnostic information influencing patient management. The aim of this study was to evaluate a novel EGFR-targeting protein, the $Z_{\text {EGFR:1907 Affibody molecule, }}$ for radionuclide imaging of EGFR expression, to determine a suitable tracer format (dimer or monomer) and optimal label. Methods: An EGFR-specific Affibody molecule, $Z_{\text {EGFR:1907, }}$ and its dimeric form, $\left(Z_{\text {EGFR:1907 }}\right)_{2}$, were labeled with ${ }^{111}$ In using benzyl-diethylenetriaminepentaacetic acid and with ${ }^{125}$ using $p$-iodobenzoate. Affinity and cellular retention of conjugates were evaluated in vitro. Biodistribution of radiolabeled Affibody molecules was compared in mice bearing EGFR-expressing A431 xenografts. Specificity of EGFR targeting was confirmed by comparison with biodistribution of non-EGFR-specific counterparts. Results: Head-to-tail dimerization of the Affibody molecule improved the dissociation rate. In vitro, dimeric forms demonstrated superior cellular retention of radioactivity. For both molecular set-ups, retention was better for the ${ }^{111} \mathrm{In}$-labeled tracer than for the radioiodinated counterpart. In vivo, all conjugates accumulated specifically in xenografts and in EGFRexpressing tissues. The retention of radioactivity in tumors was better in vivo for dimeric forms; however, the absolute uptake values were higher for monomeric tracers. The best tracer, ${ }^{111}$ In-labeled $Z_{\text {EGFR:1907, provided a tumor-to-blood ratio of } 100}$ (24 h after injection). Conclusion: The radiometal-labeled monomeric Affibody molecule $Z_{\text {EGFR:1907 }}$ has a potential for radionuclide molecular imaging of EGFR expression in malignant tumors.

Key Words: Affibody molecules; EGFR; ${ }^{125}$; ${ }^{111} \mathrm{In}$; $\gamma$-camera imaging

J Nucl Med 2009; 50:274-283

DOI: 10.2967/jnumed.108.055525

Received Jun. 29, 2008; revision accepted Nov. 17, 2008.

For correspondence or reprints contact: Vladimir Tolmachev, Biomedical Radiation Sciences, Rudbeck Laboratory, Uppsala University, S-751 81 Uppsala, Sweden.

E-mail: vladimir.tolmachev@bms.uu.se

COPYRIGHT $\odot 2009$ by the Society of Nuclear Medicine, Inc.
$\mathbf{T}$ he epidermal growth factor receptor (EGFR; other designations are HER1 and ErbB-1) is a transmembrane tyrosine kinase receptor that regulates cell proliferation, motility, and suppression of apoptosis (1). Overexpression of EGFR is documented in several malignant tumors, such as carcinomas of the breast, urinary bladder, and lung, and is associated with poor prognosis (2). A high level of EGFR expression could provide malignant cells with an advantage in survival by increasing cell proliferation, facilitating metastatic spread, and decreasing apoptosis and is considered a part of the malignant phenotype. Disruption of EGFR signaling, either by blocking EGFR binding sites on the extracellular domain or by inhibiting intracellular tyrosine kinase activity, can efficiently impede growth of EGFR-expressing tumors (3). Two anti-EGFR monoclonal antibodies are approved for routine clinical use: cetuximab (Erbitux; ImClone Systems) (4) and panitumumab (Vectibix; Amgen) (5). Detection of EGFR expression in tumors may influence patient management by providing prognostic information and, possibly, by stratifying patients for antiEGFR therapy. EGFR staining by immunohistochemistry has not been shown to be an effective method of selecting patients for treatment (5). The use of radionuclide molecular imaging for detection of EGFR expression may help to avoid such biopsy-associated pitfalls as sampling errors and discordance in EGFR expression between primary tumors and metastases.

Earlier, both anti-EGFR monoclonal antibodies (6-10) and one of the natural ligands of EGFR, the epidermal growth factor (EGF) $(6,8,11-14)$, had been proposed and evaluated as targeting agents for radionuclide imaging of EGFR overexpression. A general concern was normal expression of EGFR in healthy organs and tissues, but EGFR-expressing tumors were successfully imaged. Generally, the small (6-kDa) radiolabeled EGF provided better tumor-to-organ ratios (imaging contrast) than did bulky monoclonal antibodies and enabled imaging after a shorter 
time after injection. These data are consistent with other observations that smaller targeting agents (e.g., antibody fragments) provide better contrast because of more rapid extravasation and tumor penetration on the one hand and more rapid blood clearance on the other. However, an agonistic action of EGF may be of concern.

One novel class of promising agents for in vivo targeting is Affibody molecules (Affibody $\mathrm{AB})$, small $(\sim 7-\mathrm{kDa})$ affinity proteins based on a scaffold derived from the B domain of protein A $(15,16)$. Several studies demonstrated that radiolabeled HER2-specific Affibody molecules can be successfully used for imaging of HER2 in murine xenografts and in humans (17-20). The robust structure of Affibody molecules enabled labeling without deteriorating the binding capacity, and the small size made it possible to obtain high-contrast images of HER2 expression in xenografts within $1 \mathrm{~h}$ after injection. We have recently reported on the selection of an EGFR-specific Affibody molecule,

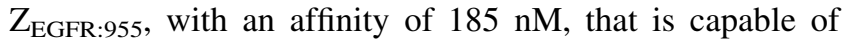
specific binding to EGFR-expressing cultured tumor cells (21). Because an affinity in the low nanomolar range is considered a precondition for successful tumor imaging

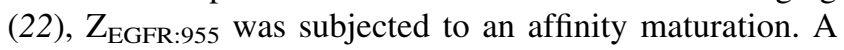
new binder, $Z_{\mathrm{EGFR}: 1907}$, with an equilibrium dissociation constant of $5.4 \mathrm{nM}$ (determined using surface plasmon resonance technology), was obtained (23).

Once a promising targeting protein is found, further optimization of a tracer is generally required. For example, di- or multimerization is a common approach for improving tumor-targeting properties of single-chain $\mathrm{Fv}$ fragments $(24,25)$. Selection of the radionuclide is also important, because the radionuclide influences the retention of radioactivity after internalization of conjugates in malignant cells (12) and in normal tissues, for example, excretory organs (26).

The goal of this study was to find a suitable tracer for radionuclide imaging of EGFR expression in malignant tumors using the second-generation EGFR-specific Affibody molecule $Z_{\mathrm{EGFR}: 1907}$. Because good tumor retention using dimers has proven to be advantageous, but small size is also of importance (27-29), we tested which factor was the most important for $Z_{\mathrm{EGFR}: 1907}$ in vivo. A dimeric form$\left(\mathrm{Z}_{\mathrm{EGFR}: 1907}\right)_{2}$-was generated, and cellular retention of monomeric and dimeric forms labeled with residualizing ${ }^{111} \mathrm{In}$ and nonresidualizing ${ }^{125} \mathrm{I}$ was evaluated in vitro. Tumor-targeting properties of 4 variants- ${ }^{111}$ In-benzyldiethylenetriaminepentaacetic acid (Bz-DTPA)-Z $Z_{\text {EGFR:1907, }}$ ${ }^{125} \mathrm{I}$ - $p$-iodobenzoate $\quad$ (PIB)-Z $Z_{\text {EGFR:1907, }}{ }^{111}$ In-Bz-DTPA$\left(\mathrm{Z}_{\mathrm{EGFR}: 1907}\right)_{2}$, and ${ }^{125} \mathrm{I}-\mathrm{PIB}-\left(\mathrm{Z}_{\mathrm{EGFR}: 1907}\right)_{2}$-were directly compared in nude mice bearing EGFR-expressing A431 cervical carcinoma xenografts.

\section{MATERIALS AND METHODS}

\section{Materials}

Isothiocyanate-Bz-DTPA was purchased from Macrocyclics. $N$-succinimidyl- $p$-(trimethylstannyl)-benzoate was synthesized in our laboratory according to a method described earlier (30). Non-EGFR-binding Affibody molecules, monomeric $\mathrm{Z}_{\mathrm{Taq}}$, and dimeric $\left(\mathrm{Z}_{\mathrm{A \beta}}\right)_{2}$, which were used in the biodistribution study as negative controls, were produced as described earlier $(31,32)$. ${ }^{111}$ In-indium chloride was purchased from Covidien and ${ }^{125} \mathrm{I}-$ sodium iodide from GE Healthcare. The EGFR-rich squamous carcinoma cell line A431 was obtained from European Collection of Cell Cultures (flow cytometric analysis and in vivo studies) and American Type Culture Collection (studies on cellular processing). Silica gel-impregnated glass fiber sheets for instant thinlayer chromatography (ITLC-SG) were from Gelman Sciences Inc. Statistical analysis of data on cellular uptake and biodistribution was performed using GraphPad Prism (version 4.00 for Windows; GraphPad Software) to determine significant differences $(P<0.05)$.

\section{Instrumentation}

The radioactivity was measured using an automated $\gamma$-counter with a 7.62-cm (3-in) thallium-doped sodium iodide detector (1480 WIZARD; Wallac Oy). In the dual-isotope biodistribution experiments, ${ }^{125}$ I radioactivity was measured in the energy window from 10 to $60 \mathrm{keV}$, and ${ }^{111} \mathrm{In}$ was measured from 100 to $450 \mathrm{keV}$. The data were corrected for dead time, spillover, and background. Distribution of radioactivity along the ITLC strips was measured on a Cyclone Storage Phosphor System (PerkinElmer) and analyzed using the OptiQuant image-analysis software (Packard). The Affibody molecules were analyzed by high-performance liquid chromatography and online mass spectrometry (HPLC-MS) using a 1100 LC/ MSD system (Agilent Technologies) equipped with electrospray ionization and a single-mass quadropol detector. Analysis and evaluation were performed with Chemstation (B.02.01; Agilent). Affinity of Affibody molecules to EGFR was analyzed both by a Biacore 2000 instrument (GE Healthcare) and by flow cytometry, which was performed on a FACSCanto II (BD Biosciences). Samples were illuminated with a Sapphire 488-20 laser (Coherent), and the fluorescence - the forward- and side-scattered light from 10,000 cells-was detected at a rate of approximately 150 events $\mathrm{s}^{-1}$. Flow cytometric data were analyzed with FACSDiva Software (BD Biosciences).

Production and Characterization of Affibody Molecules

The EGFR-binding Affibody molecule $Z_{\text {EGFR:1907 }}$ (23) and a dimeric form, $\left(Z_{\mathrm{EGFR}: 1907}\right)_{2}$, in which a second gene fragment was introduced head to tail according to a previously described method (21), were expressed as His $_{6}$-tagged fusion proteins in Escherichia coli BL21(DE3) cells and purified with immobilized metal ion affinity chromatography (IMAC) (described in detail in Friedman et al. (23)). $Z_{\text {EGFR:1907 }}$ and ( $\left.Z_{\text {EGFR:1907 }}\right)_{2}$ were also produced with a unique cysteine introduced at the $C$ terminus, $Z_{\text {EGFR:1907-cys and }}$ ( $\left.\mathrm{Z}_{\mathrm{EGFR}: 1907}\right)_{2}$-cys, as previously described (23). To confirm the purity and correct molecular mass of the proteins, $Z_{\mathrm{EGFR}: 1907}$ and $\left(Z_{\text {EGFR:1907 }}\right)_{2}$ were analyzed using a sodium dodecylsulfonatepolyacrylamide gel electrophoresis gel (NuPAGE 4\%-12\% BisTris Gel; Invitrogen) and HPLC-MS. Protein concentrations were determined by amino acid analysis (Aminosyraanalyscentralen).

Biacore was used to perform a real-time biospecific interaction analysis between the Affibody molecules and soluble extracellular domain of EGFR (EGFR-ECD), essentially as previously described (23). The $\left(\mathrm{Z}_{\mathrm{EGFR}: 1907}\right)_{2}$ Affibody molecule was further subjected to kinetic analysis, in which the protein was injected over the EGFR-ECD surface at concentrations ranging from 3.91 to $500 \mathrm{nM}$, with a flow rate of $50 \mu \mathrm{L} / \mathrm{min}$. The samples were run 
in duplicates, and after each injection the flow cells were regenerated by the injection of $10 \mu \mathrm{L}$ of $10 \mathrm{mM}$ hydrogen chloride. Off-rate determination was performed with BIAevaluation software (GE Healthcare).

\section{Flow Cytometry}

$\mathrm{Z}_{\mathrm{EGFR}: 1907}$ and $\left(\mathrm{Z}_{\mathrm{EGFR}: 1907}\right)_{2}$ were labeled directly to the unique C-terminal cysteine with Alexa Fluor 488 (Invitrogen), according to a previously described method (23). Preserved binding performance was verified for the labeled Affibody molecules using Biacore. A cell-binding study was performed essentially as described (23), in which different concentrations (ranging from 0.0488 to $50 \mathrm{nM})$ of Alexa Fluor 488 -conjugated $\left(Z_{\text {EGFR:1907 }}\right)_{2}$ and $\mathrm{Z}_{\mathrm{EGFR}: 1907}$ were incubated with $\mathrm{A} 431$ cells for $1 \mathrm{~h}$ at room temperature and analyzed with flow cytometry. Triplicates of the mean fluorescence-intensity determinations were analyzed with GraphPad Prism 5, calculating the apparent dissociation constant $\left(\mathrm{K}_{\mathrm{D}}\right)$ from an equilibrium binding curve using a nonlinear regression 1-site-specific model.

\section{Labeling Chemistry}

For labeling with ${ }^{111} \mathrm{In}$, an isothiocyanate-Bz-DTPA chelator was conjugated to Affibody molecules according to previously described methods (18). The chelator-to-protein molar ratio during conjugation was $1: 1$, which provided a coupling efficiency of about $95 \%$. For labeling, $50 \mu \mathrm{g}$ of conjugate (Bz-DTPA-Z $Z_{\text {EGFR:1907, }}$ Bz-DTPA-(Z $\left.\mathrm{Z}_{\mathrm{EGFR}: 1907}\right)_{2}$, Bz-DTPA-Z $\mathrm{Z}_{\mathrm{Taq}}$, or Bz-DTPA- $\left.\left(\mathrm{Z}_{\mathrm{A} \beta}\right)_{2}\right)$ was mixed with a predetermined amount of ${ }^{111}$ In and incubated at room temperature for $60 \mathrm{~min}$. For quality control of the labeling, ITLC-SG eluted with $0.2 \mathrm{M}$ citric acid was used. The radiochemical purity of all conjugates was more than $95 \%$, and they were used without additional purification. Stability of ${ }^{111}$ In chelation was confirmed by a challenge with a 500-fold molar excess of ethylenediaminetetraacetic acid during $4 \mathrm{~h}$ (performed in duplicate). ITLC analysis did not reveal any release of ${ }^{111}$ In from conjugates after the challenge.

Indirect radioiodination of Affibody molecules ( $\mathrm{Z}_{\mathrm{EGFR}: 1907}$, ( $\left.\mathrm{Z}_{\mathrm{EGFR}: 1907}\right)_{2}, \mathrm{Z}_{\mathrm{Taq}}$, or $\left.\left(\mathrm{Z}_{\mathrm{A} \beta}\right)_{2}\right)$ using $N$-succinimidyl-p-(trimethylstannyl)-benzoate was performed according to the method of Orlova et al. (17) and purified using NAP-5 columns (GE Healthcare). The labeling conditions were selected to provide an average attachment of a single pendant group per protein molecule. For quality control of the labeling, ITLC-SG eluted with $70 \%$ acetone in water was used. The labeling yields were $30 \%-45 \%$, and the radiochemical purity of all conjugates was more than $95 \%$.

The identity of radiolabeled monomeric and dimeric conjugates was confirmed by size-exclusion HPLC (Supplemental Figures 1-3; supplemental materials are available online only at http:// jnm.snmjournals.org).

\section{Cell-Binding and Retention Studies}

Binding specificity of radiolabeled Affibody molecules was verified by incubation of cultured EGFR-expressing A431 cells with radiolabeled Affibody molecules ( ${ }^{111}$ In-Bz-DTPA$\mathrm{Z}_{\text {EGFR:1907, }}{ }^{111}$ In-Bz-DTPA-(Z $\left.\mathrm{Z}_{\text {EGFR:1907 }}\right)_{2}, \quad{ }^{125}$ I-PIB-Z $Z_{\text {EGFR:1907, }}$ and ${ }^{125}$ I-PIB-( $\left.\left.Z_{\text {EGFR:1907 }}\right)_{2}\right)$ using a 1:1 molar ratio of Affibody molecule to EGFR receptor for $1 \mathrm{~h}$ at $37^{\circ} \mathrm{C}$. For blocking experiments, a 100-fold excess of unlabeled Affibody molecule was added $5 \mathrm{~min}$ before the addition of radiolabeled ones. All assays were performed in triplicate.
To study the cellular retention of radioactivity after interrupted incubation of radiolabeled Affibody molecules, cultured A431 cells were incubated for $2 \mathrm{~h}$ at $37^{\circ} \mathrm{C}$ with ${ }^{111} \mathrm{In}-\mathrm{Bz}-\mathrm{DTPA}-$ $\mathrm{Z}_{\text {EGFR:1907, }}{ }^{111}$ In-Bz-DTPA-(Z ${ }_{\text {EGFR:1907) }},{ }^{125}$ I-PIB-Z $Z_{\text {EGFR:1907, }}$, and ${ }^{125} \mathrm{I}-\mathrm{PIB}-\left(\mathrm{Z}_{\mathrm{EGFR}: 1907}\right)_{2}$. The Petri dishes were subsequently washed 6 times with cold serum-free culture medium, fresh complete medium was added, and the cells were incubated at $37^{\circ} \mathrm{C}$. At predetermined times, incubation medium was collected from 3 culture dishes; cells were washed 6 times with a serum-free medium and detached by trypsin treatment. The radioactivity associated with the cells and the culture medium was measured. The fraction of the cell-associated radioactivity was analyzed as a function of time.

\section{Biodistribution in Tumor-Bearing Mice}

The animal experiments were planned and performed in accordance with Swedish legislation on laboratory animals' protection, and the study plans were approved by the local Ethics Committee for Animal Research in Uppsala. In all experiments on tumor-bearing mice, female outbreed BALB/c $n u / n u$ mice were used. Xenografts of the EGFR-expressing A431 cervical carcinoma cell line were established by subcutaneous injection of $10^{7}$ cells implanted on the hind leg, and the tumors were grown for 10-14 d before the experiment. At the time of biodistribution, the average tumor size was $0.20 \pm 0.11 \mathrm{~g}$.

The mice were randomized into groups of 4 . Two groups of mice were injected intravenously with $100 \mu \mathrm{L}$ of phosphatebuffered saline solution containing a mixture of ${ }^{111} \mathrm{In}-\mathrm{Bz}-\mathrm{DTPA}-$ $\mathrm{Z}_{\text {EGFR:1907 }}(20 \mathrm{kBq})$ and ${ }^{125}$ I-PIB-Z ${ }_{\text {EGFR:1907 }}(60 \mathrm{kBq})$. Two groups of mice were injected intravenously with $100 \mu \mathrm{L}$ of phosphate-buffered saline solution containing a mixture of ${ }^{111} \mathrm{In}$ Bz-DTPA-(Z $\mathrm{ZGFR:1907}_{2}(20 \mathrm{kBq})$ and ${ }^{125} \mathrm{I}-\mathrm{PIB}-\left(\mathrm{Z}_{\mathrm{EGFR}: 1907}\right)_{2}(60$ $\mathrm{kBq})$. Non-EGFR-binding Affibody molecules were used as negative controls, in which 1 group was injected with a mixture of ${ }^{111} \mathrm{In}-\mathrm{Bz}-\mathrm{DTPA}-\mathrm{Z}_{\mathrm{Taq}}(20 \mathrm{kBq})$ and ${ }^{125} \mathrm{I}_{-\mathrm{PIB}-\mathrm{Z}_{\mathrm{Taq}}}(60 \mathrm{kBq})$ and another with a mixture of ${ }^{111} \mathrm{In}-\mathrm{Bz}-\mathrm{DTPA}-\left(\mathrm{Z}_{\mathrm{A} \beta}\right)_{2}(20 \mathrm{kBq})$ and ${ }^{125} \mathrm{I}-\mathrm{PIB}-\left(\mathrm{Z}_{\mathrm{A} \beta}\right)_{2}(60 \mathrm{kBq})$. The amount of protein injected was adjusted with nonlabeled Affibody molecules to provide an injection of $3 \mu \mathrm{g}$ of protein per mouse. The mice were sacrificed by exsanguination via heart puncture after a lethal injection of ketamine (Ketalar; Pfizer) $(50 \mathrm{mg} / \mathrm{mL})$ and xylazine (Rompun; Bayer) $(20 \mathrm{mg} / \mathrm{mL})$. Biodistribution of radioactivity after injection of radiolabeled $\mathrm{Z}_{\mathrm{EGFR}: 1907}$ and $\left(\mathrm{Z}_{\mathrm{EGFR}: 1907}\right)_{2}$ was measured at 4 and $24 \mathrm{~h}$ after injection. Animals in the negative control groups (radiolabeled $\mathrm{Z}_{\mathrm{Taq}}$ and $\left.\left(\mathrm{Z}_{\mathrm{A \beta}}\right)_{2}\right)$ were sacrificed $4 \mathrm{~h}$ after injection. The organs were excised and weighed, and their radioactivity content was measured in a $\gamma$-counter. The use of $\gamma$-spectroscopy enabled the biodistribution measurement of ${ }^{111} \mathrm{In}$ and ${ }^{125} \mathrm{I}$ in each animal independently. Radioactivity uptake was calculated as percentage of injected activity per gram of tissue (\%IA/g).

To evaluate if a saturation of EGFR in the liver can improve the tumor imaging, the biodistribution of ${ }^{111}$ In-Bz-DTPA$\left(\mathrm{Z}_{\text {EGFR:1907 }}\right)_{2}$ and ${ }^{111} \mathrm{In}-\mathrm{Bz}-\mathrm{DTPA}-\mathrm{Z}_{\mathrm{EGFR}: 1907}$ was additionally studied at 4 and $24 \mathrm{~h}$ after an injection of $50 \mu \mathrm{g}$ of each conjugate.

\section{$\gamma$-Camera Imaging}

To obtain a visual confirmation of biodistribution results, $\gamma$-camera imaging of A431 xenografts was performed using the conjugates providing the best tumor-to-blood ratios. One mouse was injected with ${ }^{111} \mathrm{In}-\mathrm{Bz}-\mathrm{DTPA}-\mathrm{Z}_{\mathrm{EGFR}: 1907}$ and another with 
${ }^{111}$ In-Bz-DTPA-(ZEGFR:1907) ${ }_{2}(3 \mathrm{MBq}, 3 \mu \mathrm{g})$. The animals were euthanized $24 \mathrm{~h}$ after injection with a lethal dose of ketamine and xylazine, and the urinary bladders were excised. Simultaneous imaging was performed using a Millennium $\gamma$-camera (GE Healthcare) equipped with a medium-energy general-purpose collimator. The scintigraphic results were evaluated visually and analyzed quantitatively using Hermes software (Nuclear Diagnostics). Quantitative analysis was performed by drawing equal regions of interest over the tumor and the contralateral thigh. Tumor-to-nontumor ratios were calculated on the basis of average count per pixel in a region of interest.

\section{RESULTS}

\section{Production and Characterization of the Affibody Molecules}

The $\mathrm{Z}_{\mathrm{EGFR}: 1907}(8.1 \mathrm{kDa})$ and $\left(\mathrm{Z}_{\mathrm{EGFR}: 1907}\right)_{2}(14.6 \mathrm{kDa})$ Affibody molecules were produced in $E$. coli and purified using IMAC. HPLC-MS analyses confirmed purity and correct molecular masses. The chromatograms are presented in the supplemental figures. Deconvolution of massspectrometry data suggested a molecular weight of 8,052.6

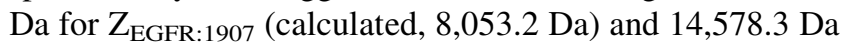
for $\left(Z_{E G F R: 1907}\right)_{2}$ (calculated, 14,580.2 Da). The difference between experimental and calculated values is within the accuracy of the method.

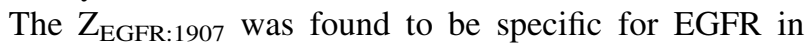
biosensor and dot-blot analysis, because no cross-reactivity was observed for other members of the EGFR family or 16 other serum proteins (23).

Affinity measurements were performed both with biosensor analysis using Biacore and with a flow cytometrymediated cell-binding assay (as described earlier for the monomeric $\mathrm{Z}_{\mathrm{EGFR}: 1907}$, by Friedman et al. (23)). It was not possible, however, to determine the $\mathrm{K}_{\mathrm{D}}$ of the dimer accurately using Biacore because of poor complete curve fitting. Dimerization of $\mathrm{Z}_{\mathrm{EGFR}: 1907}\left(\mathrm{k}_{\mathrm{a}}=1.2 \times 10^{5} \mathrm{M}^{-1} \mathrm{~s}^{-1}\right.$, $\left.\mathrm{K}_{\mathrm{D}}=6.3 \times 10^{-4} \mathrm{~s}^{-1}(21)\right)$ resulted expectedly in a substantial improvement of the dissociation rate $\left(\mathrm{K}_{\mathrm{D}}=\right.$ $\left.6.6 \times 10^{-6} \mathrm{~s}^{-1}\right)($ Fig. 1A).

Different concentrations of fluorophore-labeled $Z_{\text {EGFR:1907 }}$ and $\left(Z_{\text {EGFR:1907 }}\right)_{2}$ were allowed to bind $A 431$ cells and were then analyzed by flow cytometry. Thereafter, the $\mathrm{K}_{\mathrm{D}}$ was estimated from equilibrium-binding curves of mean fluorescence intensities: $\mathrm{K}_{\mathrm{D}}=2.8 \pm 0.1 \mathrm{nM}$ for $\mathrm{Z}_{\mathrm{EGFR}: 1907}$ (Fig. 1B) and $1.6 \pm 0.1 \mathrm{nM}$ for $\left(\mathrm{Z}_{\mathrm{EGFR}: 1907}\right)_{2}$ (Fig. 1C). The $K_{D}$ values for the monomer were thus concordant using the 2 methods for affinity determination. The $K_{D}$ for the dimer was twice better than that of the monomer.

\section{Cell-Binding and Retention Studies}

The binding of all variants of radiolabeled EGFRspecific Affibody molecules ( ${ }^{111} \mathrm{In}-\mathrm{Bz}-\mathrm{DTPA}-\mathrm{Z}_{\mathrm{EGFR}: 1907}$, ${ }^{111}$ In-Bz-DTPA-(Z $\left.Z_{\text {EGFR:1907 }}\right)_{2}, \quad{ }^{125}$ I-PIB-Z ${ }_{\text {EGFR:1907, }}$ and ${ }^{125}$ I-PIB-(Z $\left.Z_{\text {EGFR:1907 }}\right)$ to EGFR-expressing A431 cells was significantly $(P<0.0001)$ reduced when cells were
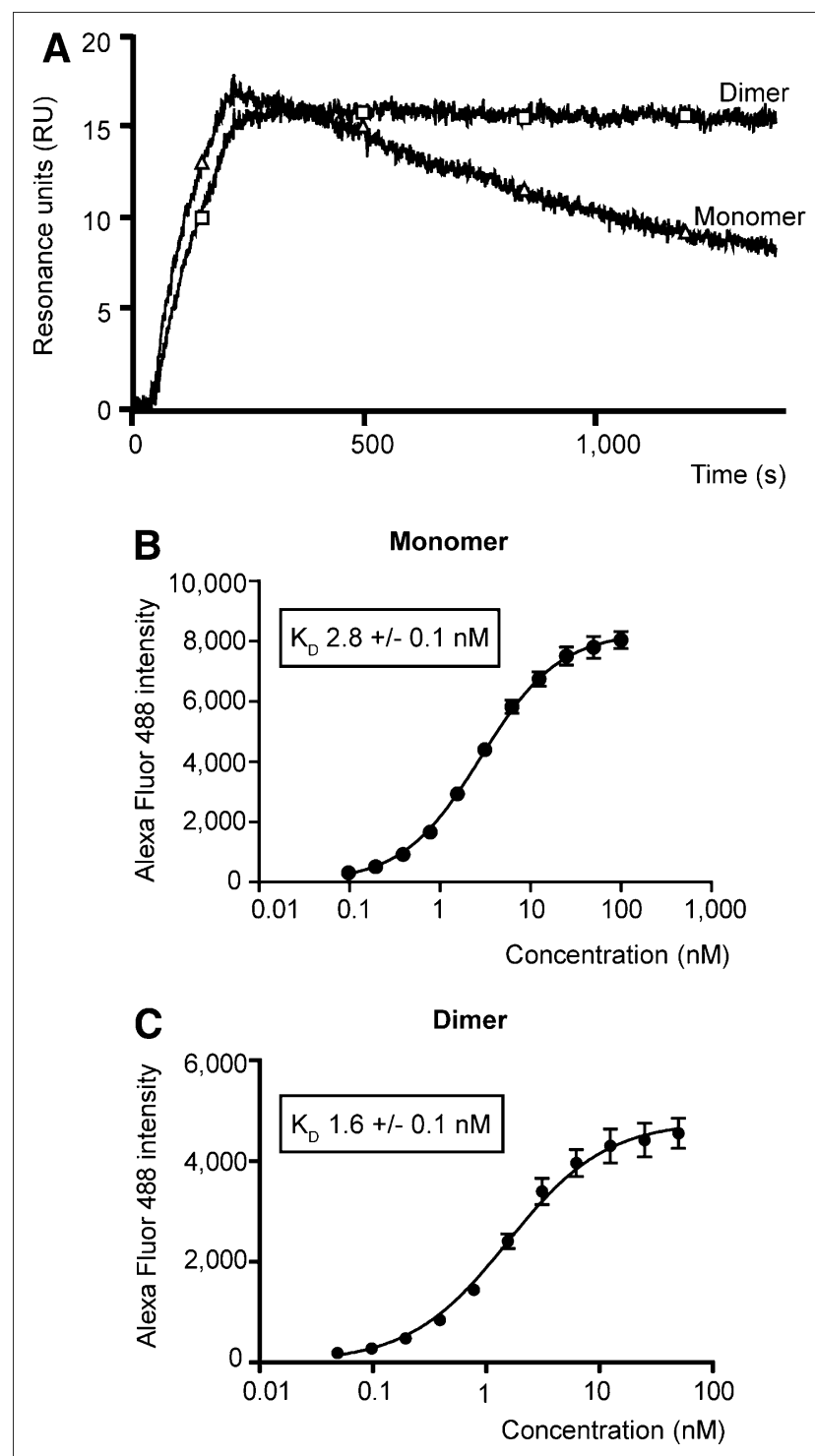

FIGURE 1. Binding and affinity analysis of $Z_{\text {EGFR:1907 }}$ monomer and dimer using surface plasmon resonance (Biacore) and flow cytometry. (A) Biacore sensorgrams obtained after injection of purified $Z_{\text {EGFR:1907 }}$ monomer $(\triangle)$ and $Z_{\text {EGFR:1907 }}$ dimer $(\square)$ at $62.5 \mathrm{nM}$ over sensor chip flowcell surface containing amine-coupled EGFR-ECD. (B and C) Flow cytometric analysis and affinity measurements of EGFR-binding Affibody molecules to EGFR on A431 cells. Affibody molecules were fluorescently labeled site specifically to C-terminally introduced cysteine with Alexa Fluor 488. Equilibrium-binding curve for $Z_{\text {EGFR:1907 monomer }(B)}$ and dimer (C). Data are average from 3 experiments and SD.

incubated in advance with a large excess of nonlabeled counterpart. This demonstrated that the binding could be saturated, which is evidence of the EGFR-specific binding.

Cellular retention of radiolabeled Affibody molecules is presented in Figure 2. Unfortunately, the conventional methods for removal of membrane-bound radioactivity (acid wash, displacement with nonlabeled tracer) were inefficient for Affibody dimer. For this reason, a direct 
FIGURE 2. Cellular retention of radioactivity after interrupted incubation of EGFR-expressing A431 cells with EGFR-targeting Affibody molecules. Data are average value from 3 Petri dishes and SD. Error bars might not be seen because they are smaller than point symbols.

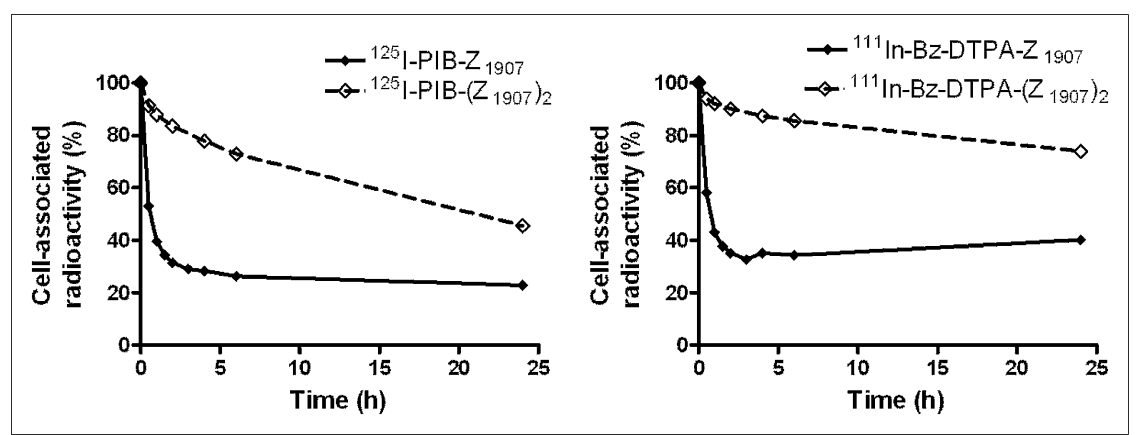

assessment of internalized radioactivity was not possible, and the influence of internalization on retention of radioactivity was deduced. The cellular retention of dimeric forms was better than that for monomeric ones, independent of the label type ( ${ }^{111}$ In-Bz-DTPA or ${ }^{125}$ I-PIB). The residualizing ${ }^{111}$ In label provided somewhat better cellular retention in comparison with nonresidualizing radioiodine label.

\section{Biodistribution in Tumor-Bearing Mice}

The biodistribution data and the results of their statistical treatment are presented in Tables 1 and 2. The common feature of all conjugates, both EGFR-specific and negative control, was a rapid blood clearance (less than 2 percentage injected dose per gram in blood $4 \mathrm{~h}$ after injection) and predominantly renal excretion of the radioactivity with subsequent reabsorption in kidneys. At the same time, there were significant differences in the biodistribution of conjugates. Thus, at $4 \mathrm{~h}$ after injection the tumor uptake of all specific conjugates was appreciably and significantly higher than the uptake of control non-EGFR-specific Affibody molecules that had been labeled in the same way. This is evidence of the in vivo specificity of tumor accumulation. The uptake of EGFR-specific conjugates was also significantly higher in organs and tissues with normal physiologic expression of EGFR, such as the liver, spleen, and gastrointestinal tract, which demonstrated the reactivity of the Affibody molecules with murine EGFR.

The radioactivity concentration of ${ }^{111}$ In was generally higher than that of ${ }^{125} \mathrm{I}$ in normal organs and tissues. The most prominent difference was in the kidneys, in which the ${ }^{111}$ In radioactivity was 21 -fold higher for monomeric and more than 7-fold for dimeric forms at $4 \mathrm{~h}$ after injection. Twenty-four hours after injection, the ${ }^{125}$ I radioactivity was nearly completely cleared from the kidneys $(<1$ percentage injected dose per gram), whereas the indium radioactivity was retained. Indium-labeled monomer accumulated to a lesser extent than did the dimer in the liver, spleen, and gastrointestinal tract, but the uptake in the kidneys was higher.

At $4 \mathrm{~h}$ after injection, tumor uptake of the monomeric form was higher than that of the dimeric form for both labels. Furthermore, the tumor uptake was higher for ${ }^{111} \mathrm{In}$ - labeled monomer than for ${ }^{125}$ I-labeled monomer. Also at $24 \mathrm{~h}$ after injection, the use of ${ }^{111}$ In provided higher tumor radioactivity concentration than did ${ }^{125} \mathrm{I}$ for both the monomer and the dimer. Tumor-to-organ ratios were generally better for a monomeric form (Fig. 3). The best tumor-toorgan ratios (except for tumor-to-kidney ratio) were provided by ${ }^{111} \mathrm{In}-\mathrm{Bz}-\mathrm{DTPA}-\mathrm{Z}_{\mathrm{EGFR}: 1907}$ ( $24 \mathrm{~h}$ after injection).

The increase of the amount of injected conjugate from 3 to $50 \mu \mathrm{g}$ had a pronounced influence on the biodistribution of both ${ }^{111} \mathrm{In}-\mathrm{Bz}-\mathrm{DTPA}-\mathrm{Z}_{\mathrm{EGFR}: 1907}$ and ${ }^{111} \mathrm{In}-\mathrm{Bz}-\mathrm{DTPA}-$ $\left(Z_{\text {EGFR:1907) }}\right.$ (Table 3). Hepatic uptake was significantly reduced for both conjugates because of saturation of EGFR in the liver. At the same time, the renal excretion of conjugates increased, resulting in elevated reabsorption of radioactivity in kidneys. The radioactivity concentration in blood and several other tissues was lower for both monomer and dimer after an injection of $50 \mu \mathrm{g}$. The influence of injected amount on tumor uptake of ${ }^{111} \mathrm{In}-\mathrm{Bz}-\mathrm{DTPA}-\mathrm{Z}_{\mathrm{EGFR}: 1907}$ and ${ }^{111}$ In-Bz-DTPA- $\left(Z_{\text {EGFR:1907 }}\right)_{2}$ was different. The tumor uptake of monomer decreased somewhat at $4 \mathrm{~h}$ after injection, indicating partial blocking of EGFR also in xenografts. The tumor uptake of dimer increased, probably because of the increased bioavailability of the conjugate. However, the tumor-to-organ ratios were higher for monomeric ${ }^{111} \mathrm{In}$ Bz-DTPA-Z $Z_{\text {EGFR:1907 }}$ also at this protein dose level (Figs. $3 \mathrm{C}$ and $3 \mathrm{D})$.

\section{$\gamma$-Camera Imaging}

$\gamma$-Camera imaging, performed at $24 \mathrm{~h}$ after injection, confirmed the results of the biodistribution experiments. The most prominent site of radioactivity accumulation for both ${ }^{111}$ In-Bz-DTPA-Z $Z_{\text {EGFR:1907 }}$ and ${ }^{111}$ In-Bz-DTPA( $\left.\mathrm{Z}_{\mathrm{EGFR}: 1907}\right)_{2}$ was the kidneys. The EGFR-expressing tumor xenografts were visualized using both conjugates. However, the use of ${ }^{111}$ In-Bz-DTPA-Z $Z_{\text {EGFR } 1907}$ provided better contrast in the images. Tumor-to-contralateral site ratios were 6.8 for ${ }^{111} \mathrm{In}-\mathrm{Bz}-\mathrm{DTPA}-\mathrm{Z}_{\mathrm{EGFR}: 1907}$ and 3.2 for ${ }^{111} \mathrm{In}-\mathrm{Bz}-$

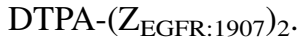

\section{DISCUSSION}

The sensitivity of radionuclide imaging is determined by the contrast, that is, the ratio of radioactivity concentration in tumors and healthy tissues. This ratio depends on many characteristics of the targeting agent, such as binding 


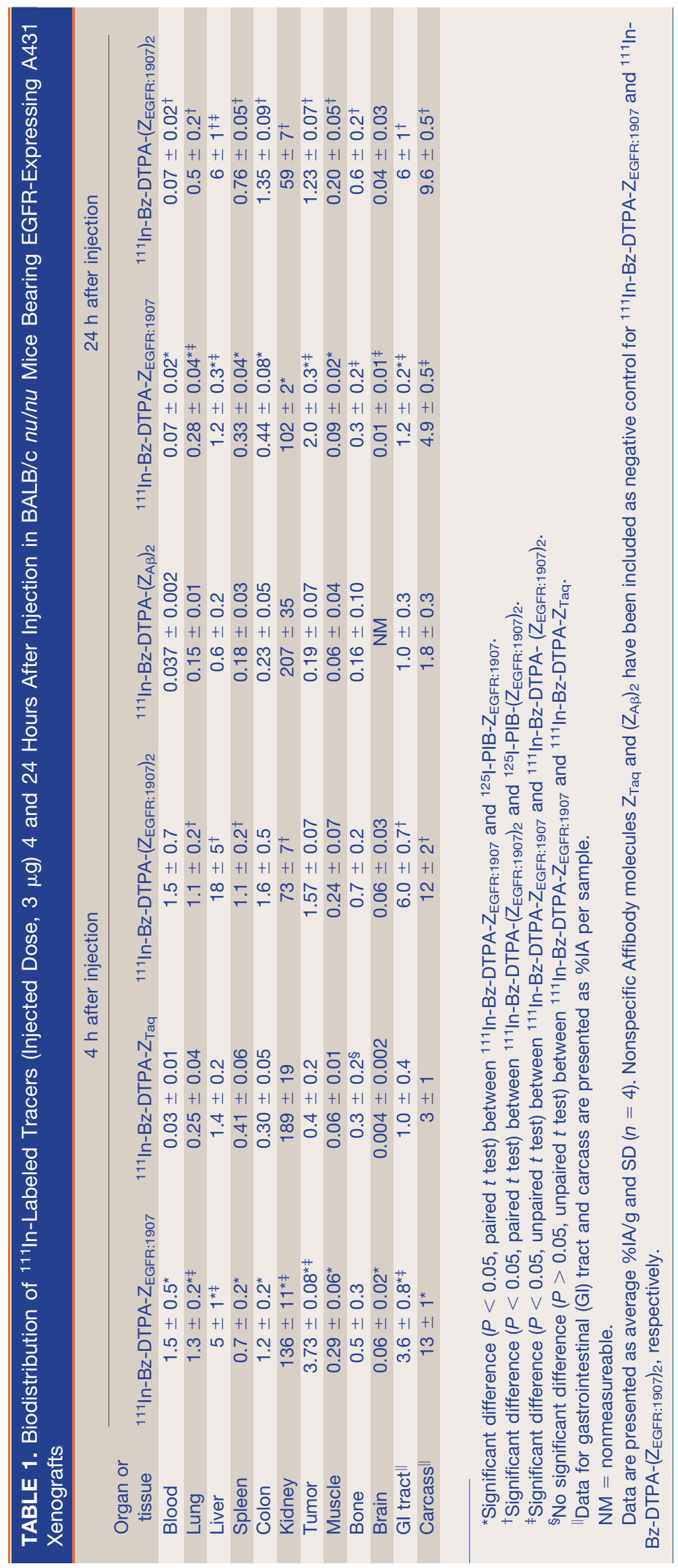


TABLE 2. Biodistribution of ${ }^{125}$ /-Labeled Tracers (Injected Dose, $\left.3 \mu \mathrm{g}\right) 4$ and 24 Hours After Injection in BALB/c $n u / n u$ Mice Bearing EGFR-Expressing A431 Xenografts

\begin{tabular}{|c|c|c|c|c|c|c|}
\hline \multirow[b]{2}{*}{ Blood or tissue } & \multicolumn{4}{|c|}{$4 \mathrm{~h}$ after injection } & \multicolumn{2}{|c|}{$24 \mathrm{~h}$ after injection } \\
\hline & $\overline{125 I-P I B-Z} Z_{\text {EGFR:1907 }}$ & ${ }^{125} \mathrm{I}-\mathrm{PIB}-\mathrm{Z}_{\mathrm{Taq}}$ & ${ }^{125} \mathrm{I}-\mathrm{PIB}-\left(Z_{\text {EGFR:1907) }}\right)_{2}$ & ${ }^{125}$ I-PIB- $\left(Z_{A \beta}\right)_{2}$ & 125I-PIB-Z $Z_{\text {EGFR:1907 }}$ & ${ }^{125}$ I-PIB-(Z \\
\hline Blood & $1.2 \pm 0.3^{\star}$ & $0.25 \pm 0.02$ & $1.1 \pm 0.5$ & $0.052 \pm 0.003$ & $0.04 \pm 0.01^{*}$ & $0.04 \pm 0.01^{\dagger}$ \\
\hline Lung & $0.9 \pm 0.2^{*}$ & $0.12 \pm 0.03$ & $1.0 \pm 0.2^{\dagger}$ & $0.04 \pm 0.01$ & $0.05 \pm 0.02^{*}$ & $0.05 \pm 0.02^{\dagger}$ \\
\hline Liver & $2.1 \pm 0.7^{\star \ddagger}$ & $0.21 \pm 0.03$ & $6 \pm 2^{\dagger}$ & $0.05 \pm 0.01$ & $0.06 \pm 0.01^{\star \neq} \neq$ & $0.3 \pm 0.2^{\dagger}$ \\
\hline Spleen & $0.31 \pm 0.08^{*}$ & $0.11 \pm 0.02$ & $0.4 \pm 0.2^{\dagger}$ & $0.065 \pm 0.002$ & $0.05 \pm 0.02^{*}$ & $0.04 \pm 0.02^{\dagger}$ \\
\hline Colon & $0.47 \pm 0.10^{\star} \ddagger$ & $0.10 \pm 0.07$ & $0.73 \pm 0.10$ & $0.05 \pm 0.02$ & $0.02 \pm 0.01^{*}$ & $0.09 \pm 0.10^{\dagger}$ \\
\hline Kidney & $6.3 \pm 0.6^{\star \ddagger}$ & $7 \pm 2^{\S}$ & $10 \pm 2^{\dagger}$ & $6 \pm 2$ & NM & $0.6 \pm 0.2^{\dagger}$ \\
\hline Tumor & $2.48 \pm 0.10^{\star \ddagger}$ & $0.2 \pm 0.1$ & $1.9 \pm 0.4$ & $0.07 \pm 0.05$ & $0.26 \pm 0.07^{\star \neq} \neq$ & $0.46 \pm 0.09^{\dagger}$ \\
\hline Muscle & $0.16 \pm 0.06^{\star}$ & $0.03 \pm 0.01$ & $0.17 \pm 0.03$ & $0.02 \pm 0.01$ & $0.02 \pm 0.01^{*}$ & $0.02 \pm 0.02^{\dagger}$ \\
\hline Bone & $0.34 \pm 0.10$ & $0.09 \pm 0.03$ & $0.32 \pm 0.02$ & NM & $0.14 \pm 0.10$ & NM \\
\hline Brain & $0.04 \pm 0.0^{\star}$ & $0.02 \pm 0.02 \S$ & $0.05 \pm 0.01$ & $0.01 \pm 0.01$ & $0.01 \pm 0.0^{\ddagger}$ & $0.010 \pm 0.003$ \\
\hline Gl tract $\|$ & $1.8 \pm 0.5^{\star}$ & $0.8 \pm 0.4$ & $2.5 \pm 0.2^{\dagger}$ & $0.5 \pm 0.2$ & $0.07 \pm 0.01^{\star \neq}$ & $0.18 \pm 0.09^{\dagger}$ \\
\hline Carcass\| & $7 \pm 1^{*}$ & $1.15 \pm 0.09$ & $8 \pm 1^{\dagger}$ & $0.7 \pm 0.2$ & $0.6 \pm 0.1$ & $1.4 \pm 0.2^{\dagger}$ \\
\hline $\begin{array}{l}\text { *Significant diff } \\
{ }^{\dagger} \text { Significant dif } \\
\text { †Significant dif } \\
\text { \$No significant } \\
\text { "Data for gastr } \\
\text { NM = nonmea } \\
\text { Data are prese }\end{array}$ & $\begin{array}{l}\text { ference }(P<0.05, \mathrm{p} \\
\text { ference }(P<0.05, \mathrm{u} \\
\text { ference }(P<0.05, \mathrm{u} \\
\text { difference }(P>0.05 \\
\text { ointestinal (Gl) tract } \\
\text { surable. } \\
\text { nted as average \%|A } \\
\text { B-Z } Z_{\text {EGFR: } 1907 \text { and }{ }^{125}}\end{array}$ & $\begin{array}{l}\text { aired } t \text { test) be } \\
\text { inpaired } t \text { test) } \\
\text { unpaired } t \text { test) } \\
5 \text {, unpaired } t \text { te } \\
\text { and carcass a } \\
\text { Vg and SD ( } n=\end{array}$ & $\begin{array}{l}\text { etween }{ }^{111} \text { In-Bz-DTPA } \\
\text { between }{ }^{111} \text { In-Bz-DT } \\
\text { between }{ }^{125} \text { I-PIB-DT } \\
\text { est) between }{ }^{125} \text { I-PIB-Z } \\
\text { are presented as \% IA } \\
=4 \text { ). Nonspecific Affibo } \\
\text { 907) }{ }_{2} \text {, respectively. }\end{array}$ & $\begin{array}{l}\text { A-Z } \\
\text { PA-(Z:1907 and } \\
\text { PA-Z } \\
\text { PAGFR:1907)2 } \\
Z_{\text {EGFR:1907 }} \text { and } \\
\text { per sample. } \\
\text { ody molecules Z }\end{array}$ & 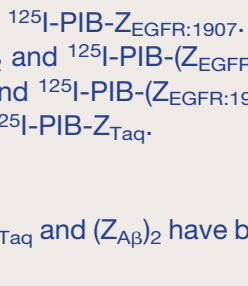 & $\begin{array}{l}\text { R:1907)2. } \\
\text { 907)2. }\end{array}$ \\
\hline
\end{tabular}

strength, properties of the label during cellular processing, tumor localization rate, clearance from normal organs, and biologic properties of the target. An important parameter is the level of retention of radioactivity by the malignant cells, when a nonbound targeting agent is cleared from blood and healthy tissues. Retention depends, in turn, on the rate of dissociation of a tracer from target and on cellular processing of the tracer-target complex. Di- or multimerization of targeting proteins usually decreases the dissociation rate. In several examples, this enhanced tumor localization of the tracer has been shown to outweigh the negative effects of increased size on distribution and penetration $(24,28,33,34)$.

In this study, Biacore measurements demonstrated that dimerization substantially improved the off-rate of the $Z_{\text {EGFR:1907 }}$ (Fig. 1A). The increased retention of the dimeric form was also seen in living cells during comparative
FIGURE 3. Tumor-to-organ ratios after injection of radiolabeled anti-EGFR Affibody molecules in BALB/c nu/nu mice bearing EGFR-expressing xenografts at $4 \mathrm{~h}$ after injection and injected dose of $3 \mu \mathrm{g}(\mathrm{A}), 24 \mathrm{~h}$ after injection and injected dose of $3 \mu \mathrm{g}(\mathrm{B}), 4 \mathrm{~h}$ after injection and injected dose of $50 \mu \mathrm{g}(\mathrm{C})$, and $24 \mathrm{~h}$ after injection and injected dose of $50 \mu \mathrm{g}(\mathrm{D})$. Data are average of 4 animals and SD.

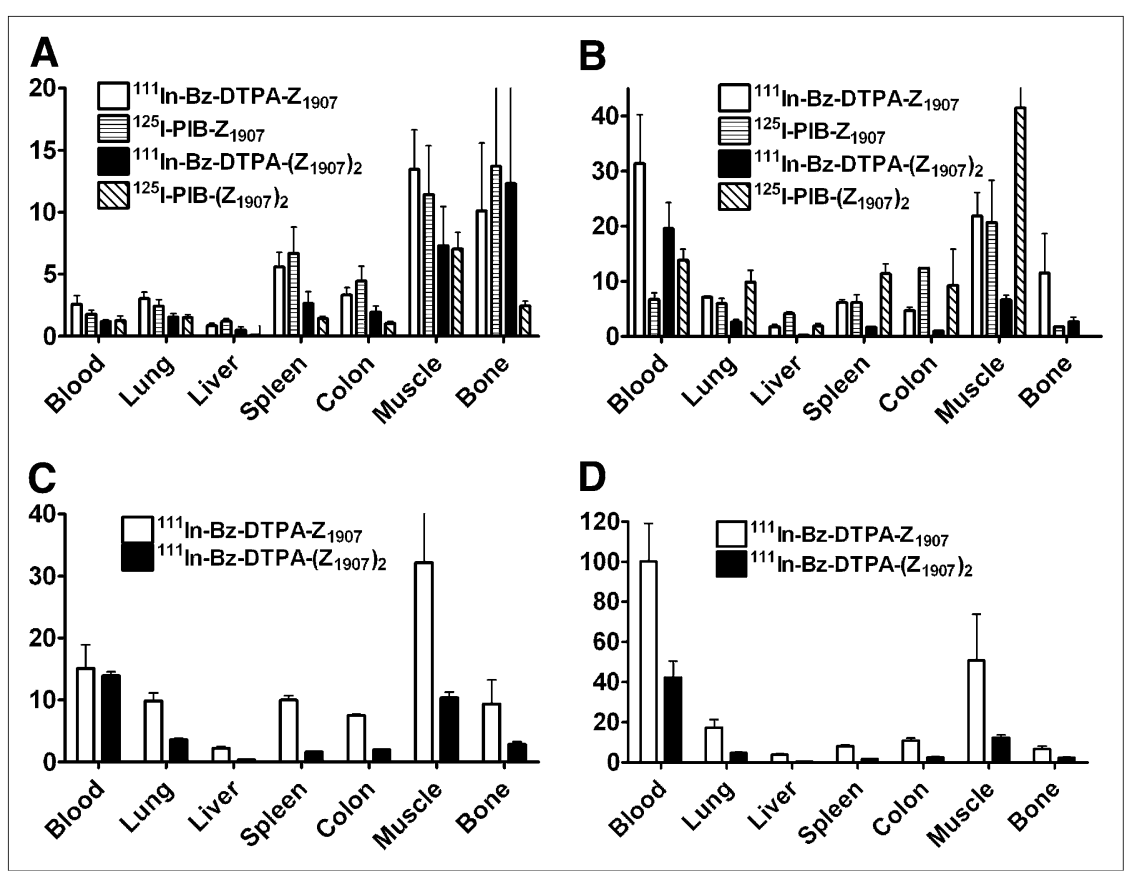




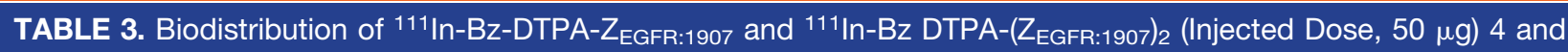

24 Hours After Injection in BALB/c nu/nu Mice Bearing EGFR-Expressing A431 Xenografts

\begin{tabular}{|c|c|c|c|c|}
\hline \multirow[b]{2}{*}{ Organ or tissue } & \multicolumn{2}{|c|}{$4 \mathrm{~h}$ after injection } & \multicolumn{2}{|c|}{$24 \mathrm{~h}$ after injection } \\
\hline & $\overline{\text { 111/n-Bz-DTPA-Z }_{\text {EGFR:1907 }}}$ & ${ }^{111} \mathrm{In}-\mathrm{Bz}-\mathrm{DTPA}-\left(\mathrm{Z}_{\mathrm{EGFR}: 1907)_{2}}\right.$ & $\overline{{ }^{111} \mathrm{In}-\mathrm{Bz}-\mathrm{DTPA}-\mathrm{Z}_{\text {EGFR:1907 }}}$ & ${ }^{111} \mathrm{In}-\mathrm{Bz}-\mathrm{DTPA}-\left(\mathrm{Z}_{\text {EGFR:1907 }}\right)_{2}$ \\
\hline Blood & $0.23 \pm 0.05^{*}$ & $0.18 \pm 0.03^{*}$ & $0.025 \pm 0.006^{\star}$ & $0.038 \pm 009^{*}$ \\
\hline Lung & $0.34 \pm 0.03^{\star}+$ & $0.68 \pm 0.09^{*}$ & $0.14 \pm 0.03^{*}+$ & $0.33 \pm 0.06$ \\
\hline Liver & $1.5 \pm 0.2^{\star \dagger}$ & $6.9 \pm 1.2^{*}$ & $0.7 \pm 0.1^{* \dagger}$ & $3.6 \pm 1.4$ \\
\hline Spleen & $0.34 \pm 0.02^{\star \dagger}$ & $1.5 \pm 0.2$ & $0.29 \pm 0.02^{\dagger}$ & $1.0 \pm 0.3$ \\
\hline Colon & $0.45 \pm 0.01^{* \dagger}$ & $1.2 \pm 0.2$ & $0.22 \pm 0.02^{\star \dagger}$ & $0.6 \pm 0.1^{*}$ \\
\hline Kidney & $196 \pm 4^{*}$ & $169 \pm 32^{*}$ & $120 \pm 10^{*}$ & $118 \pm 14^{*}$ \\
\hline Tumor & $3.35 \pm 0.08^{\star \dagger}$ & $2.43 \pm 0.35^{\star}$ & $2.39 \pm 0.06^{\dagger}$ & $1.5 \pm 0.3$ \\
\hline Muscle & $0.12 \pm 0.05^{\star \dagger}$ & $0.24 \pm 0.05$ & $0.05 \pm 0.02^{\dagger}$ & $0.13 \pm 0.04$ \\
\hline Bone & $0.4 \pm 0.1^{\star \dagger}$ & $0.9 \pm 0.3$ & $0.37 \pm 0.08^{\dagger}$ & $0.7 \pm 0.3$ \\
\hline Brain & $0.013 \pm 0.004^{\star \dagger}$ & $0.020 \pm 0.003^{*}$ & NM & $0.010 \pm 0.005^{\star}$ \\
\hline Gl tract ${ }^{\ddagger}$ & $1.7 \pm 0.3^{\star} \dagger$ & $3.5 \pm 0.5^{\star}$ & $0.6 \pm 0.1^{\star} \dagger$ & $1.4 \pm 0.1^{*}$ \\
\hline Carcass $^{\ddagger}$ & $3.8 \pm 0.4^{*+}$ & $9.0 \pm 1.0$ & $2.0 \pm 0.3^{\star \dagger}$ & $5.8 \pm 1.3^{*}$ \\
\hline $\begin{array}{l}{ }^{*} \text { Significant diff } \\
{ }^{\dagger} \text { Significant dif } \\
{ }^{\ddagger} \text { Data for gastr } \\
\text { NM }=\text { nonmea } \\
\text { Data are prese }\end{array}$ & $\begin{array}{l}\text { erence ( } P<0.05 \text {, paired } t \text { t } \\
\text { erence }(P<0.05 \text {, unpaired } \\
\text { ointestinal }(\mathrm{Gl}) \text { tract and car } \\
\text { surable. } \\
\text { ted as average } \% \mathrm{IA} / \mathrm{g} \text { and }\end{array}$ & $\begin{array}{l}\text { est) between uptake after inj } \\
t \text { test) between }{ }^{111} \text { In-Bz-DTP } \\
\text { cass are presented as \%IA p } \\
\text { SD }(n=4) .\end{array}$ & $\begin{array}{l}\text { tion of } 3 \text { and } 50 \mu \mathrm{g} \text { of tra } \\
-Z_{\text {EGFR:1907 and }}{ }^{111} \ln -B z-[ \\
\text { sample. }\end{array}$ & $\begin{array}{l}\text { er. } \\
\text { IPA-(Z }\end{array}$ \\
\hline
\end{tabular}

evaluation of radiolabeled monomers and dimers in vitro (Fig. 2).

The cellular processing of EGFR-specific Affibody molecules by malignant cells is another important issue to consider. Binding of the natural ligand (EGF) to EGFR causes rapid internalization, trafficking into lysosomes, and subsequent degradation of EGF. Lipophilic radiocatabolites can diffuse through lysosomal and cellular membranes and "leak" from the malignant cells, as, for example, in the case of radiohalogen labels $(12,35)$. In the case of a radiometal label, bulky charged radiocatabolites of labeled EGF cannot penetrate membranes and remain trapped in the cell, resulting in favorable retention $(12,14,36,37)$. However, a radiometal label does not offer improved tumor retention if the internalization into malignant cells is a slow clathrin-independent process (generally observed with antagonistic binders). On the contrary; the larger retention may even be a negative property because of high retention in the excretory organs, such as the liver and kidney (26). In this case, a slow off-rate would provide better cellular retention of radioactivity and, consequently, better imaging contrast. In the current study, some differences in the in vitro cellular retention were observed between radioiodinated and radiometal-labeled conjugates (Fig. 2). However, these differences were much smaller than in the case of radiolabeled EGF $(12,37)$. These smaller differences indicate that the internalization of the Affibody moleculeEGFR complex in vitro is relatively slow both for monomers and for dimers. Increased cellular retention in the case of dimeric forms showed that a slow off-rate was important to retain a high level of cell-associated radioactivity. Thus, the results of in vitro studies were in favor of using the dimeric form.
In vivo biodistribution data after injection of $3 \mu \mathrm{g}$ of conjugates (Tables 1 and 2), particularly the comparison with non-EGFR specific Affibody molecules, demonstrated that all conjugates bind in vivo to EGFR-overexpressing xenografts and normal EGFR-expressing tissues. Nonspecific conjugates cleared rapidly from all tissues and were reabsorbed in the kidneys. As expected, the renal retention of the residualizing indium label was higher than that of iodine. In the liver, spleen, and gastrointestinal tract, the uptake of EGFR-specific conjugates was significantly higher than the uptake of nonspecific tracers, suggesting receptor-mediated uptake. Moreover, these tissues demonstrated saturable uptake of ${ }^{111}$ In-labeled EGF in earlier studies (38). An elevated blood level of the specific conjugates, compared with nonspecific ones, may be attributed to tracers dissociating from EGFR-expressing tissues over time. However, the blood-borne radioactivity was to a high extent cleared $24 \mathrm{~h}$ after injection. The most interesting observation was the significantly higher tumor accumulation of monomeric $Z_{\mathrm{EGFR}: 1907}$ in comparison with dimeric $\left(\mathrm{Z}_{\mathrm{EGFR}: 1907}\right)_{2}$ at $4 \mathrm{~h}$ after injection, for both labels. For this reason, tumor-to-organ ratios were generally higher for

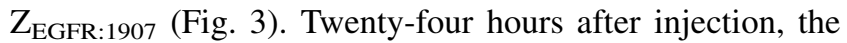
contrast was appreciably improved because of clearance from blood and nontumor compartments. The residualizing effect of radiometal was more pronounced in vivo than in vitro. Despite a better cellular retention of radioactivity for dimeric forms, the better tumor localization of the smaller monomer, together with high cellular retention of the radiometal label, resulted in ${ }^{111} \mathrm{In}-\mathrm{Bz}-\mathrm{DTPA}-\mathrm{Z}_{\mathrm{EGFR}: 1907}$ providing the best tumor-to-organ ratios. A superior visualization of EGFR-expression in A431 by monomer, compared with dimer, was also confirmed in $\gamma$-camera study (Fig. 4). 


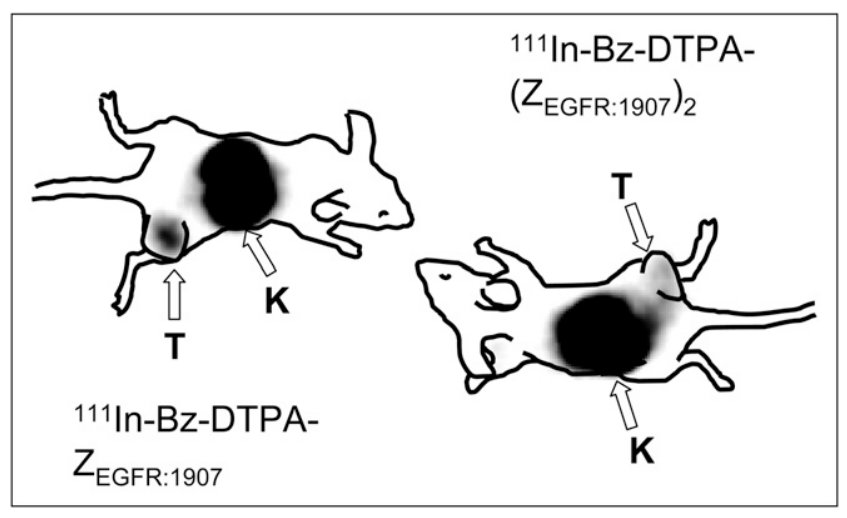

FIGURE 4. Imaging of EGFR expression in A431 xenografts in BALB/c nude mice using ${ }^{111}$ In-Bz-DTPA- $Z_{1907}$ and ${ }_{111}$ In-Bz-DTPA- $\left(Z_{1907}\right)_{2}$. Planar $\gamma$-camera images were collected $24 \mathrm{~h}$ after administration of tracers. Arrows point to tumors $(\mathrm{T})$ and kidneys $(\mathrm{K})$.

Clinical studies showed that EGFR expression in the liver might be a barrier in the targeting of EGFR-expressing tumors, and an increased amount of antibodies was required for efficient imaging (39). This study demonstrated that an increase in the injected amount of Affibody molecules from 3 to $50 \mu \mathrm{g}$ increased the tumor-to-organ ratios (except for the kidneys) (Fig. 3). Saturation of the liver depot might reduce the amount of radiolabeled conjugates that dissociate from the liver and reenter the circulation. As the result, the radioactivity concentration in blood and other tissues did decrease after injection of $50 \mu \mathrm{g}$ of conjugates (Table $3)$. The blocking effect of such an amount on the tumor uptake of ${ }^{111}$ In-Bz-DTPA-Z $Z_{\text {EGFR:1907 }}$ was relatively small, and the tumor uptake of ${ }^{111}$ In-Bz-DTPA-( $\left.Z_{\text {EGFR: } 1907}\right)_{2}$ even increased, presumably because of better availability of conjugate. However, even at this dosage level $(50 \mu \mathrm{g})$, ${ }^{111}$ In-Bz-DTPA-Z $Z_{\text {EGFR:1907 was superior as an imaging }}$ agent, providing a tumor-to-blood ratio of $100 \pm 19(24 \mathrm{~h}$ after injection).

A possible limitation of ${ }^{111} \mathrm{In}-\mathrm{Bz}-\mathrm{DTPA}-\mathrm{Z}_{\mathrm{EGFR}: 1907}$ is a high accumulation of radioactivity in the kidneys. This accumulation might complicate imaging of tumors in the vicinity of the kidneys because of reconstruction artifacts. This problem is also shared with many diagnostic radiometal-labeled peptides.

\section{CONCLUSION}

A radiometal-labeled monomeric form of $\mathrm{Z}_{\mathrm{EGFR}: 1907}$ is the preferable format of an EGFR-specific Affibody molecule for imaging and shows promise for clinical applications.

\section{ACKNOWLEDGMENTS}

This research was financially supported by grants from the Swedish Cancer Society Cancerfonden (grant CAN 2006/1212) and the Swedish Governmental Agency for Innovation Systems, VINNOVA (grant P25882-1).

\section{REFERENCES}

1. Yarden Y, Sliwkowski MX. Untangling the ErbB signalling network. Nat Rev Mol Cell Biol. 2001;2:127-137.

2. Nicholson RI, Gee JM, Harper ME. EGFR and cancer prognosis. Eur J Cancer. 2001;37(suppl):S9-S15.

3. Castillo L, Etienne-Grimaldi MC, Fischel JL, Formento P, Magne N, Milano G. Pharmacological background of EGFR targeting. Ann Oncol. 2004;15:1007-1012.

4. Calvo E, Rowinsky EK. Approaches to optimize the use of monoclonal antibodies to epidermal growth factor receptor. Curr Oncol Rep. 2005;7:123-128.

5. Chua YJ, Cunningham D. Panitumumab. Drugs Today (Barc). 2006;42:711-719.

6. Senekowitsch-Schmidtke R, Steiner K, Haunschild J, Mollenstadt S, Truckenbrodt R. In vivo evaluation of epidermal growth factor (EGF) receptor density on human tumor xenografts using radiolabeled EGF and anti-(EGF receptor) mAb 425. Cancer Immunol Immunother. 1996;42:108-114.

7. Morales-Morales A, Duconge J, Caballero-Torres I, Nunez-Gandolff G, Fernandez E, Iznaga-Escobar N. Biodistribution of ${ }^{99 m}$ Tc-labeled anti-human epidermal growth factor receptor (EGF-R) humanized monoclonal antibody h-R3 in a xenograft model of human lung adenocarcinoma. Nucl Med Biol. 1999;26:275-279.

8. Reilly RM, Kiarash R, Sandhu J, et al. A comparison of EGF and MAb 528 labeled with ${ }^{111}$ In for imaging human breast cancer. J Nucl Med. 2000;41:903-911.

9. Perk LR, Visser GW, Vosjan MJ, et al. ${ }^{89} \mathrm{Zr}$ as a PET surrogate radioisotope for scouting biodistribution of the therapeutic radiometals ${ }^{90} \mathrm{Y}$ and ${ }^{177} \mathrm{Lu}$ in tumorbearing nude mice after coupling to the internalizing antibody cetuximab. $\mathrm{J} \mathrm{Nucl}$ Med. 2005;46:1898-1906.

10. Cai W, Chen K, He L, Cao Q, Koong A, Chen X. Quantitative PET of EGFR expression in xenograft-bearing mice using ${ }^{64} \mathrm{Cu}$-labeled cetuximab, a chimeric anti-EGFR monoclonal antibody. Eur J Nucl Med Mol Imaging. 2007;34:850858.

11. Hnatowich DJ, Qu T, Chang F, Ley AC, Ladner RC, Rusckowski M. Labeling peptides with technetium-99m using a bifunctional chelator of a N-hydroxysuccinimide ester of mercaptoacetyltriglycine. J Nucl Med. 1998;39:56-64.

12. Orlova A, Bruskin A, Sjöström A, Lundqvist H, Gedda L, Tolmachev V. Cellular processing of ${ }^{125} \mathrm{I}$ and ${ }^{111} \mathrm{In}$ labeled epidermal growth factor (EGF) bound to cultured A431 tumor cells. Nucl Med Biol. 2000;27:827-835.

13. Babaei MH, Almqvist Y, Orlova A, Shafii M, Kairemo K, Tolmachev V. [ ${ }^{99 \mathrm{~m}} \mathrm{Tc}$ ] HYNIC-hEGF, a potential agent for imaging of EGF receptors in vivo: preparation and preliminary pre-clinical evaluation. Oncol Rep. 2005;13:1169-1175.

14. Velikyan I, Sundberg AL, Lindhe Ö, et al. Preparation and evaluation of ${ }^{68} \mathrm{Ga}-$ DOTA-hEGF for visualization of EGFR expression in malignant tumors. $\mathrm{J} \mathrm{Nucl}$ Med. 2005;46:1881-1888.

15. Nilsson FY, Tolmachev V. Affibody molecules: new protein domains for molecular imaging and targeted tumor therapy. Curr Opin Drug Disc Devel. 2007;10:167-175.

16. Tolmachev V, Orlova A, Nilsson FY, Feldwisch J, Wennborg A, Abrahmsen L. Affibody molecules: potential for in vivo imaging of molecular targets for cancer therapy. Expert Opin Biol Ther. 2007;7:555-568.

17. Orlova A, Magnusson M, Eriksson T, et al. Tumor imaging using a picomolar affinity HER2 binding Affibody molecule. Cancer Res. 2006;66:4339-4348.

18. Tolmachev V, Nilsson FY, Widström C, et al. ${ }^{111}$ In-benzyl-DTPA-Z $Z_{\text {HER } 2: 342}$, an Affibody-based conjugate for in vivo imaging of HER2 expression in malignant tumors. J Nucl Med. 2006;47:846-853.

19. Orlova A, Tolmachev V, Pehrson R, et al. Synthetic Affibody molecules: a novel class of affinity ligands for molecular imaging of HER2 expressing malignant tumors. Cancer Res. 2007;67:2178-2186.

20. Baum RP, Orlova A, Tolmachev V, Feldwisch J. A novel molecular imaging agent for diagnosis of recurrent HER2 positive breast cancer: first time in human study using an indium-111- or gallium-68-labeled Affibody molecule [abstract]. Eur J Nucl Med Mol Imaging. 2006;33(suppl 14):S91.

21. Friedman M, Nordberg E, Hoiden-Guthenberg I, et al. Phage display selection of Affibody molecules with specific binding to the extracellular domain of the epidermal growth factor receptor. Protein Eng Des Sel. 2007;20:189-199.

22. Behr TM, Gotthardt M, Barth A, Behe M. Imaging tumors with peptide-based radioligands. Q J Nucl Med. 2001;45:189-200.

23. Friedman M, Orlova A, Johansson E, et al. Directed evolution to low nanomolar affinity of an epidermal growth factor receptor 1-binding Affibody molecule. J Mol Biol. 2008;376:1388-1402.

24. Nielsen UB, Adams GP, Weiner LM, Marks JD. Targeting of bivalent anti-ErbB2 diabody antibody fragments to tumor cells is independent of the intrinsic antibody affinity. Cancer Res. 2000;60:6434-6440.

25. Goel A, Baranowska-Kortylewicz J, Hinrichs SH, et al. ${ }^{99} \mathrm{mTc}-$ labeled divalent and tetravalent CC49 single-chain Fv's: novel imaging agents for rapid in vivo localization of human colon carcinoma. J Nucl Med. 2001;42:1519-1527. 
26. Kenanova V, Olafsen T, Williams LE, et al. Radioiodinated versus radiometallabeled anti-carcinoembryonic antigen single-chain Fv-Fc antibody fragments: optimal pharmacokinetics for therapy. Cancer Res. 2007;67:718-726.

27. Kenanova V, Wu AM. Tailoring antibodies for radionuclide delivery. Expert Opin Drug Deliv. 2006;3:53-70.

28. Batra SK, Jain M, Wittel UA, Chauhan SC, Colcher D. Pharmacokinetics and biodistribution of genetically engineered antibodies. Curr Opin Biotechnol. 2002;13:603-608.

29. Thurber GM, Zajic SC, Wittrup KD. Theoretic criteria for antibody penetration into solid tumors and micrometastases. J Nucl Med. 2007;48:995-999.

30. Koziorowski J, Henssen C, Weinreich R. A new convenient route to radioiodinated $\mathrm{N}$-succinimidyl 3- and 4-iodobenzoate, two reagents for iodination of proteins. Appl Radiat Isot. 1998;49:955-959.

31. Gunneriusson E, Nord K, Uhlén M, Nygren P. Affinity maturation of a Taq DNA polymerase specific affibody by helix shuffling. Protein Eng. 1999;12:873-878.

32. Grönwall C, Jonsson A, Lindström S, Gunneriusson E, Ståhl S, Herne N. Selection and characterization of Affibody ligands binding to Alzheimer amyloid beta peptides. J Biotechnol. 2007;128:162-183.

33. Wu AM, Chen W, Raubitschek A, et al. Tumor localization of anti-CEA single-chain Fvs: improved targeting by non-covalent dimers. Immunotechnology. 1996;2:21-36.
34. Adams GP, Schier R, McCall AM, et al. Prolonged in vivo tumour retention of a human diabody targeting the extracellular domain of human HER2/neu. $\mathrm{Br} \mathrm{J}$ Cancer. 1998;77:1405-1412.

35. Orlova A, Sjöström A, Lebeda O, Lundqvist H, Carlsson J, Tolmachev V. Targeting against epidermal growth factor receptors: cellular processing of astatinated EGF after binding to cultured carcinoma cells. Anticancer Res. 2004;24:4035-4042.

36. Sundberg ÅL, Orlova A, Bruskin A, Gedda L, Carlsson J, Tolmachev V. [ $\left.{ }^{111} \mathrm{In}\right] \mathrm{Bz}-\mathrm{DTPA}-\mathrm{hEGF}$ : preparation and in vitro characterisation of potential antiglioblastoma targeting peptide. Cancer Biother Radiopharm. 2003;18:643-654.

37. Sundberg ÅL, Gedda L, Orlova A, et al. $\left[{ }^{177} \mathrm{Lu}\right]$ Bz-DTPA-EGF: preclinical characterization of a potential radionuclide targeting agent against glioma. Cancer Biother Radiopharm. 2004;19:195-204.

38. Tolmachev V, Orlova A, Wei Q, Bruskin A, Carlsson J, Gedda L. Comparative biodistribution of potential anti-glioblastoma conjugates [ $\left.{ }^{111} \mathrm{In}\right] \mathrm{DTPA}-\mathrm{hEGF}$ and $\left[{ }^{111} \mathrm{In}\right] \mathrm{Bz}-\mathrm{DTPA}-\mathrm{hEGF}$ in normal mice. Cancer Biother Radiopharm. 2004; 19:491-501.

39. Divgi CR, Welt S, Kris M, et al. Phase I and imaging trial of indium 111-labeled anti-epidermal growth factor receptor monoclonal antibody 225 in patients with squamous cell lung carcinoma. J Natl Cancer Inst. 1991;83:97-104. 